\title{
Role of IncRNA uc.457 in the differentiation and maturation of cardiomyocytes
}

\author{
QIJUN ZHANG ${ }^{1}$, ZIJIE CHENG $^{1}$, ZHANGBIN YU $^{2}$, CHUN ZHU $^{3}$ and LINGMEI QIAN ${ }^{1}$ \\ ${ }^{1}$ Department of Cardiology, The First Affiliated Hospital of Nanjing Medical University, Nanjing, Jiangsu 210029; \\ Departments of ${ }^{2}$ Pediatrics and ${ }^{3}$ Child Health Care, Women's Hospital of Nanjing Medical University, \\ Nanjing Maternity and Child Health Care Hospital, Nanjing, Jiangsu 210004, P.R. China
}

Received June 29, 2018; Accepted March 27, 2019

DOI: $10.3892 / \mathrm{mmr} .2019 .10132$

\begin{abstract}
Congenital heart disease (CHD) is the most common type of birth defect, and the leading cause of fetal mortality. The long noncoding RNA (lncRNA) uc.457 is differentially expressed in cardiac tissue from patients with a ventricular septal defect; however, its role in cardiac development and CHD remains unknown. In the present study, the role of uc.457 in the differentiation and maturation of cardiomyocytes was investigated. Bioinformatics approaches were employed to analyze putative transcription factor (TF) regulation, histone modifications and the biological functions of uc.457. Subsequently, uc.457 overexpression and small interfering RNA-mediated knockdown were performed to evaluate the functional role of the lncRNA in the dimethyl sulfoxide-induced differentiation of P19 cells into cardiomyocytes. Bioinformatics analyses predicted that uc. 457 binds to TFs associated with cardiomyocyte growth and cardiac development. Cell Counting Kit-8 assays demonstrated that uc. 457 overexpression inhibited cell proliferation, whereas knockdown of uc.457 enhanced the proliferation of differentiating cardiomyocytes. Additionally, reverse transcription-quantitative polymerase chain reaction and western blot analyses revealed that overexpression of uc.457 suppressed the mRNA and protein expression of histone cell cycle regulation defective homolog $\mathrm{A}$, natriuretic peptide $\mathrm{A}$, cardiac muscle troponin $\mathrm{T}$ and myocyte-specific enhancer factor $2 \mathrm{C}$. Collectively, the results indicated that overexpression of uc.457 inhibited the differentiation and
\end{abstract}

Correspondence to: Dr Lingmei Qian, Department of Cardiology, The First Affiliated Hospital of Nanjing Medical University, 300 Guangzhou Road, Nanjing, Jiangsu 210029, P.R. China

E-mail: 1mqian@njmu.edu.cn

Dr Chun Zhu, Department of Child Health Care, Women's Hospital of Nanjing Medical University, Nanjing Maternity and Child Health Care Hospital, 123 Tianfei Lane, Mochou Road, Nanjing, Jiangsu 210004, P.R. China

E-mail: zhifangxibao@163.com

Key words: uc.457, cardiomyocyte, differentiation, proliferation proliferation of cardiomyocytes, suggesting that dysregulated uc.457 expression may be associated with CHD.

\section{Introduction}

Congenital heart disease (CHD) is a structural and functional defect induced by the abnormal development of cardiovascular blood vessels. CHD is the most common type of birth defect and the leading cause of fetal mortality (1). CHD frequently leads to miscarriage, stillbirth and severe cardiopathy following birth, which seriously endangers neonatal health $(2,3)$. Ventricular septal defect (VSD) is the most common type of CHD, comprising $40 \%$ of all cardiac abnormalities (4). At present, it is hypothesized that CHD is primarily induced by a combination of genetic and environmental factors, leading to cardiac malformation at the embryonic stage; only 2-5\% of CHD cases result from environmental factors alone (5-7). Previous studies have revealed certain genes associated with cardiac developmental abnormalities, including Notch homolog 1, heart- and neural crest derivatives-expressed protein 2 (HAND2) and GATA (8); however, the precise mechanisms underlying the roles of these genes in the regulation of embryonic heart development are yet to be determined. Therefore, further study of the mechanisms underlying embryonic heart formation and development is required to develop novel strategies for the prevention of CHD.

Long noncoding RNAs (IncRNAs) comprise a group of transcripts that are $>200$ nucleotides in length. LncRNAs do not encode proteins as they lack a specific open reading frame (9). Functionally, lncRNAs regulate gene expression by influencing chromatin remodeling, transcriptional regulation, and post-transcriptional modification $(10,11)$. Previous studies have demonstrated that lncRNAs exhibit important roles in the development of the cardiovascular system and the pathogenesis of associated disorders, including myocardial infarction, heart failure, dilated cardiomyopathy and VSD $(12,13)$. For example, IncRNA cardiac hypertrophy-related factor induces cardiac hypertrophy via competitive binding to microRNA (miR)-489 (14), whereas IncRNA braveheart (Bvht) promotes stem cell differentiation during cardiac development (15).

LncRNA uc.457 is located at 22q11.21 (chr22: 19395909-19396119) and is $211 \mathrm{bp}$ in length. Our previous study reported that uc.457 is differentially expressed in 
children with VSD (16); however, its specific role in cardiac development remains unclear. P19 cells are pluripotent stem cells that can be cultured in vitro. The self-replication ability and differentiation potential of P19 cells enable them to differentiate into cardiomyocyte-like cells when induced by a low concentration of dimethyl sulfoxide (DMSO) (17). P19 cells have been widely utilized in the study of cardiac development (18).

In the present study, differentiated P19 cells were employed to investigate the effects of differential expression of uc.457 on the proliferation and differentiation of cardiomyocytes, providing novel insight into the mechanisms of cardiac development.

\section{Materials and methods}

Cell culture and transfection. Mouse embryonic carcinoma P19 cells were obtained from the American Type Culture Collection (Manassas, VA, USA). Cells were cultured in $\alpha$-minimal essential medium ( $\alpha$-MEM; Gibco; Thermo Fisher Scientific, Inc., Waltham, MA, USA) containing $10 \%$ fetal bovine serum (FBS; Gibco; Thermo Fisher Scientific, Inc.), $100 \mathrm{U} / \mathrm{ml}$ penicillin and $100 \mathrm{mg} / \mathrm{ml}$ streptomycin. Cells were maintained in a $5 \% \mathrm{CO}_{2}$ incubator at $37^{\circ} \mathrm{C}$. Cells were seeded in 6 -well plates at a density of $5 \times 10^{4}$ cells $/ \mathrm{ml}$. The medium was replaced by complete medium without antibiotics $6 \mathrm{~h}$ before transfection. Plasmids (pGPU6/GFP/Neo-uc.457 and pGPU6/GFP/Neo-siRNA-uc.457) were constructed by Shanghai GenePharma Co., Ltd., (Shanghai, China). The sequences of the 3 siRNAs were as follows: uc457-siRNA: 5'-GGGCCTTATCTTTCTAATTAC-3'; siNC: 5'-GTTCTC CGAACGTGTCACGT-3'; siGAPDH: 5'-GTATGACAA CAGCCTCAAG-3'. Cells were seeded in 6-well culture plates and grown to $70-80 \%$ confluence before transfection. Transfection was conducted according to the Lipofectamine ${ }^{\circledR}$ 2000 DNA transfection reagent protocol (Life Technologies; Thermo Fisher Scientific, Inc.). Then, $24 \mathrm{~h}$ after transfection, the confluence was approximately $90 \%$ and the cells were removed to grow in flasks (Sigma-Aldrich; Merck KGaA, Darmstadt, Germany).The cells were also collected to confirm uc.457 silencing efficiency and overexpression by reverse transcription-quantitative polymerase chain reaction (RT-qPCR).

Cardiomyocyte differentiation. P19 cells were seeded in a 10 -cm culture dish at a density of $1 \times 10^{6}$ cells $/ \mathrm{ml}$. Cardiomyocyte differentiation was induced using $\alpha$-MEM containing $1 \%$ DMSO at $37^{\circ} \mathrm{C}$. On the 4 th day post-induction, 10 embryonic bodies were seeded in 6-well plates. Autonomously beating cardiomyocyte-like cell masses were first observed on the 8th day, and were largely present by the 10th day.

Cell Counting Kit-8 (CCK-8) assay. P19 cells were seeded in 96 -well plates at a density of $3 \times 10^{4}$ cells $/ \mathrm{ml}$. CCK-8 reagent (10 $\mu \mathrm{l}$; Dojindo Molecular Technologies, Inc., Kumamoto, Japan) was added to each well for 4 consecutive days. Following incubation for a further $2 \mathrm{~h}$ at $37^{\circ} \mathrm{C}$, the optical density of each well was measured at $450 \mathrm{~nm}$ using a microplate reader (Bio-Rad Laboratories, Inc., Hercules, CA, USA).
$R N A$ extraction and RT- $q P C R$. Total RNA was isolated from cultured P19 cells using TRIzol ${ }^{\circledR}$ reagent (Thermo Fisher Scientific, Inc.) and RT was performed using a PrimeScript RT Reagent kit (Takara Bio, Inc., Otsu, Japan) according to the manufacturer's protocols. RNA concentration was determined using a spectrophotometer (Hitachi, Ltd., Tokyo, Japan) and an ABI Prism 7500 cycler. qPCR was performed using the following thermocycling conditions: $95^{\circ} \mathrm{C}$ for $30 \mathrm{sec}, 95^{\circ} \mathrm{C}$ for $5 \mathrm{sec}$ and $60^{\circ} \mathrm{C}$ for $30 \mathrm{sec}$, for a total of 40 cycles. Gene expression was measured in triplicate. The data was analyzed using the $2^{-\Delta \Delta \mathrm{Cq}}$ method (19). The relative gene expression levels were quantified based on the $\mathrm{Ct}$ and normalized to a reference gene, GAPDH. The primers used were as follows: Uc.457, forward 5'-CCTTTGCAGGCTTTGCGTG-3', reverse, 5'-CCGCAC GGGGCCTTATCTT-3'; histone cell cycle regulation defective homolog A (HIRA), forward 5'-CTGGACACTGGGTACTCA CTC-3', reverse, 5'-AACTGGCTAACTGACAACAGAAG-3'; natriuretic peptide A (NPPA), forward 5'-GCTTCCAGGCCA TATTGGAG-3', reverse, 5'-GGGGGCATGACCTCATCT T-3'; cardiac muscle troponin T (cTnT), forward 5'-CAGAGG AGGCCAACGTAGAAG-3', reverse, 5'-CTCCATCGGGGA TCTTGGGT-3'; myocyte-specific enhancer factor 2C (Mef2c), forward 5'-ATCCCGATGCAGACGATTCAG-3', reverse, 5'-AACAGCACACAATCTTTGCCT-3'; GAPDH, forward 5'-CTGCGACTTCAACAGCAACT-3', reverse, 5'-GAGTTG GGATAGGGCCTCTC-3'.

Western blotting. P19 cells were lysed using cell lysis buffer (Nanjing KeyGen Biotech Co., Ltd., Nanjing, China), agitated on ice for $30 \mathrm{~min}$ and centrifuged $(14,000 \mathrm{x} \mathrm{g})$ at $4^{\circ} \mathrm{C}$ for $15 \mathrm{~min}$. The total protein concentration was calculated using a bicinchoninic acid protein assay kit (Pierce; Thermo Fisher Scientific, Inc.). Extracted proteins (50 $\mu \mathrm{g}$ of total protein per lane) were separated via $10 \%$ SDS-PAGE and subsequently transferred onto polyvinylidene difluoride membranes (EMD Millipore, Billerica, MA, USA). The membranes were blocked with 5\% Bovine Serum Albumin (BSA; Sigma-Aldrich; Merck $\mathrm{KGaA}$ ) in TBST (50 mM tris-buffered saline, $\mathrm{pH}$ 7.5, $150 \mathrm{mM}$ $\mathrm{NaCl}, 0.05 \%$ Tween-20). The membrane was incubated at $4^{\circ} \mathrm{C}$ overnight in 5\% BSA in TBST containing primary antibodies to one of the following: HIRA (1:200; ab20655; Abcam, Cambridge, UK), NPPA (1:200; ab180649; Abcam), CTnT (1:250; ab209813; Abcam), Mef2c (1:200; ab211493; Abcam) and $\beta$-actin $(1: 1,000 ;$ ab124964; Abcam). The membrane was washed 5 times with TBST for 5 min each wash. Following washing, the membrane was incubated with horseradish peroxidase (HRP) conjugated goat anti-rabbit secondary antibody (ab6721; Abcam) at 1:5,000 dilution for $1 \mathrm{~h}$ at room temperature, then washed with TBST. Western blot analysis was performed according to standard procedures.

Bioinformatics analysis. The University of California, Santa Cruz (UCSC) Genome Browser (http://genome.ucsc.edu/) was employed to identify transcription factor (TF) binding sites, TF partners, histone modification and DNase I hypersensitive sites (indicative of open chromatin) in the uc.457 region.

Statistical analysis. Each experiment was performed at least three times. SPSS version 16.0 software (SPSS, Inc., Chicago, IL, USA) was used for data analysis. Data were presented as 


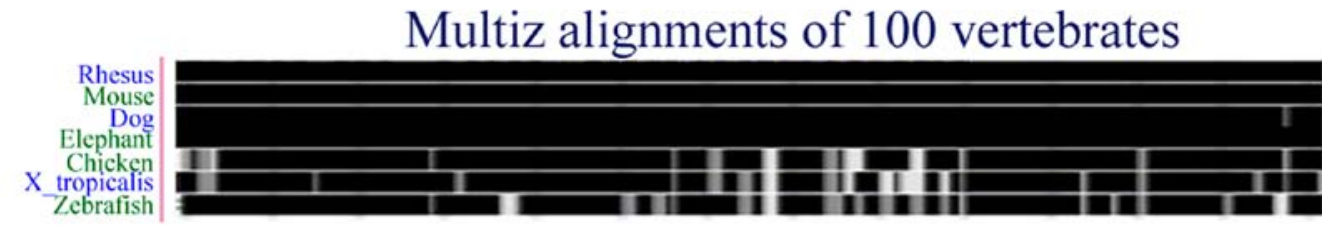

C

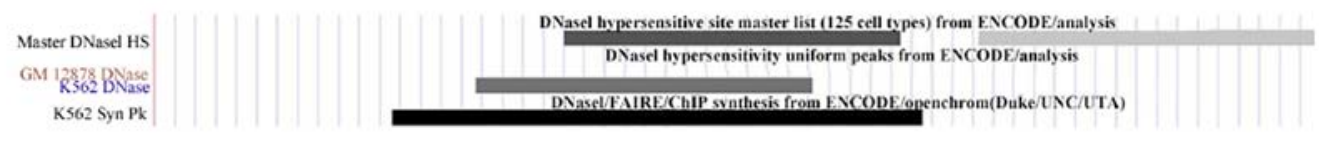

D

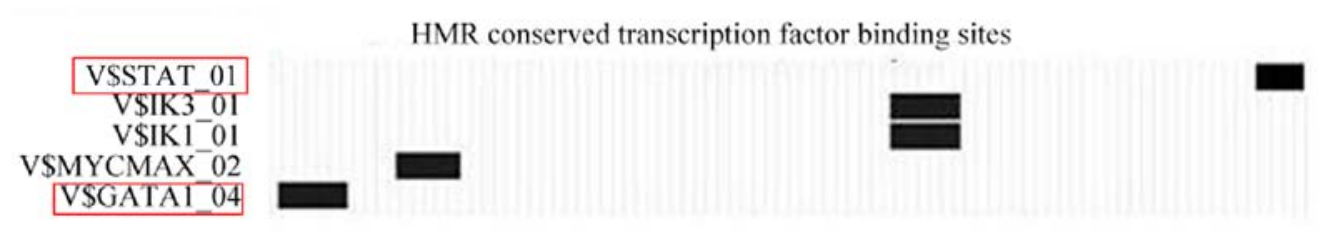

E

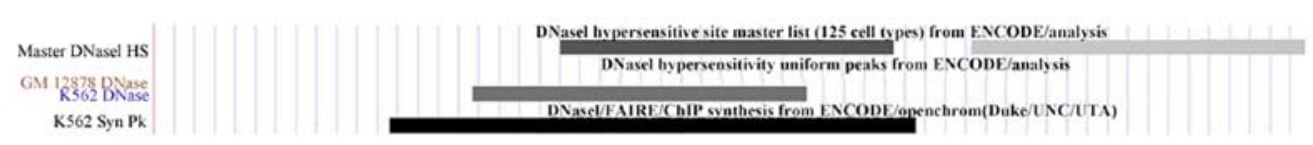

Figure 1. Genomic features of lncRNA uc.457. (A) Chromosome location of uc.457. (B) Conservation analysis of uc.457. (C) DNase I hypersensitivity analysis of uc.457. (D) Putative transcription factors regulating uc.457. (E) Histone modification analysis of uc.457. ac, acetylation; ChIP-seq, chromatin immunoprecipitation sequencing; H3K, histone 3 lysine; HMR, human, mouse and rat; lncRNA, long noncoding RNA; me, methylation.

the mean \pm standard deviation. Continuous variables were analyzed by Student's t-tests. $\mathrm{P}<0.05$ was considered to indicate a statistically significant difference.

\section{Results}

Biological predictions of uc.457. The UCSC database was employed to predict the potential biological functions of uc.457. It was revealed that uc.457 is located at $22 \mathrm{q} 11.21$ (chr22: 19395909-19396119) and is 211 bp in length (Fig. 1A). In addition, uc.457 is highly conserved among vertebrates, with identical sequences in humans, rhesus monkeys and mice (Fig. 1B). By analyzing the DNase I footprint, TFs and histone modifications, it was determined that uc. 457 contains a binding site for cis-acting elements (Fig. 1C). Uc.457 was also predicted to be regulated by signal transducer and activator of transcription (STAT) and GATA-binding factor 1 (GATA1; Fig. 1D). There were numerous histone modifications identified within the chromosomal region of uc.457, including $\mathrm{H} 3 \mathrm{~K} 4 \mathrm{me} 1, \mathrm{H} 3 \mathrm{~K} 9 \mathrm{ac}, \mathrm{H} 3 \mathrm{~K} 27 \mathrm{ac}, \mathrm{H} 3 \mathrm{~K} 27 \mathrm{me} 3$ and H3K36me3 (Fig. 1E).

Uc.457 overexpression suppresses the proliferation of P19 cells. To determine the effects of uc.457 on cardiac development, uc.457 overexpression plasmids and small interfering RNA (siRNA) against uc.457 were generated. Overexpression of uc.457 significantly inhibited the proliferation of P19 cells in a time-dependent manner, with significant decreases in absorbance observed at 48 and $72 \mathrm{~h}$ compared with transfection with green fluorescent protein (GFP)-control (pGPU6/GFP/Neo; Fig. 2A and B). Conversely, siRNA-mediated knockdown of uc.457 significantly increased the proliferation of cells compared with the control (Fig. 2C and D).

Uc.457 overexpression inhibits the differentiation of P19 cells. The mRNA expression levels of the cardiomyocyte maturation-associated genes HIRA, NPPA, cTnT and Mef2c were markedly increased over time in differentiating P19 cells, reaching a peak on the 10th day (Fig. 3); however, overexpression of uc. 457 notably suppressed. Significant reductions in expression following uc. 457 were observed from day 4 for NPPA and cTnT, and day 6 for HIRA and Mef2c compared with the control.

Uc.457 knockdown promotes the differentiation of P19 cells. To further investigate the effects of uc.457 on the differentiation of P19 cells, the mRNA expression levels of HIRA, NPPA, cTnT and Mef2c were determined following knockdown of uc.457. It was revealed that transfection with uc.457 siRNA (si-uc.457) significantly upregulated the expression of HIRA, NPPA and cTnT from 4 days, and Mef2c from 6 days in P19 cells compared with in control siRNA (si-control)-transfected cells (Fig. 4). 
A

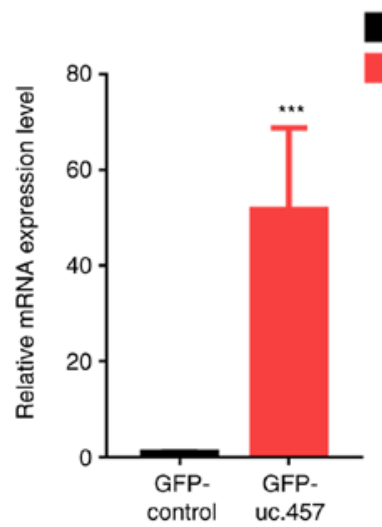

C

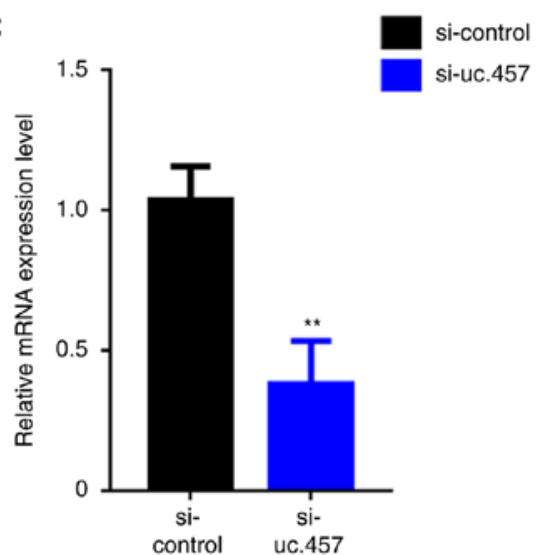

B

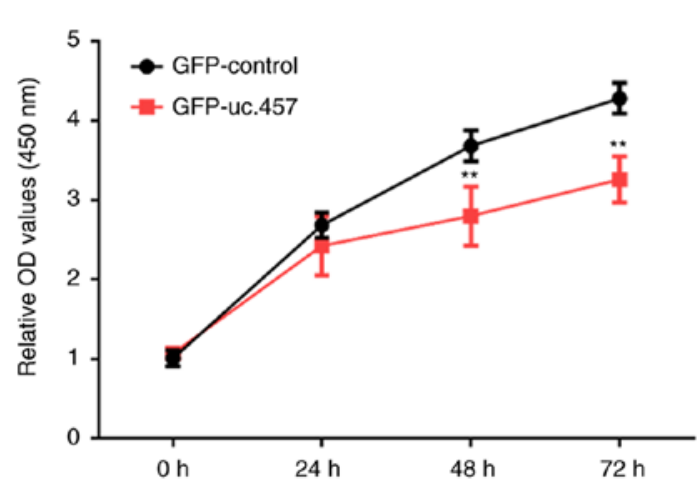

D

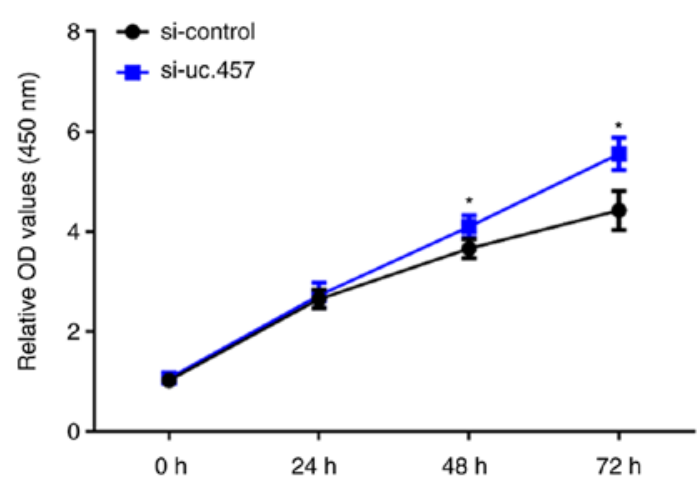

Figure 2. Uc.457 suppresses the proliferation of P19 cells. (A) Expression levels of uc.457 following transfection with GFP-uc.457 or GFP-control plasmid. mRNA expression levels were normalized to $\beta$-actin using the $2^{-\Delta \Delta \mathrm{Cq}}$ method. (B) Proliferation of cells at $0,24,48$ and $72 \mathrm{~h}$ following transfection with GFP-uc.457 and GFP-control plasmid. ${ }^{* *} \mathrm{P}<0.01,{ }^{* * *} \mathrm{P}<0.001$ vs. GFP-control. (C) Expression levels of uc. 457 following si-uc.457 or si-control transfection. (D) Proliferation of cells at $0,24,48$ and $72 \mathrm{~h}$ following transfection with si-uc. 457 or si-control. $\mathrm{N}=3$ /group. Data are presented as the mean \pm standard deviation. ${ }^{*} \mathrm{P}<0.05,{ }^{* *} \mathrm{P}<0.01$ vs. si-control. GFP, green fluorescent protein; OD, optical density; si, small interfering RNA.

Uc.457 regulates the expression of genes associated with cardiomyocyte differentiation. Western blot analysis demonstrated that the protein expression of HIRA, NPPA, cTnT, and Mef2c increased in a time-dependent manner under conditions of cell differentiation (Fig. 5). Overexpression of uc.457 in P19 cells resulted in a marked downregulation of these proteins, whereas si-uc.457 transfection was associated with upregulated expression.

\section{Discussion}

CHD is the most common type of congenital malformation in infants and young children, and is the leading cause of mortality in members of this population with non-infectious diseases (20). Cardiac development involves the migration, differentiation, proliferation and apoptosis of various types of cells, including cardiomyocytes, endocardial cells and cardiac neural crest cells (7). The development of CHD involves a precise and complex network of various TFs, cell adhesion molecules and signaling molecules $(21,22)$. A previous study demonstrated that genetic defects are the leading cause of cardiac dysplasia (23); GATA4, homeobox protein NKX2.5 and HAND2 have been identified to be associated with abnormal heart development $(24,25)$. Post-transcriptional regulation also serves an important role in heart development; noncoding RNAs are notably involved in post-transcriptional regulation (26).

It has been demonstrated the important roles of lncRNAs in embryonic and cardiovascular development (27). In the process of stem cell differentiation, LncRNA Bvht stimulates the differentiation of cardiac cells by activating a gene network that promotes the formation of pluripotent cardiac progenitor cells from cardiac mesoderm (15). Furthermore, Bvht interacts with polycomb repressive complex 2 , which in turn regulates the differentiation of cell lineages and cardiac formation (28). Additionally, IncRNA TERMINATOR regulates the differentiation state of pluripotent stem cells and regulates the function of the cardiovascular development-associated lncRNA ALIEN, whereas IncRNA PUNISHER attenuates the function of cardiac endothelial cells (29). Grote et al (30) found that the tissue-specific lncRNA Fendrr is an essential regulator of heart and body wall development in the mouse.

Our previous study identified numerous differentially expressed IncRNAs in heart tissues from patients with VSD (16). Subsequent bioinformatics analyses predicted that these IncRNAs were closely associated with cardiac development, apoptosis and proliferation; however, their biological functions were not verified. In the present study, the biological functions of uc.457 were investigated using an in vitro model. Via bioinformatics analysis, it was revealed 
A

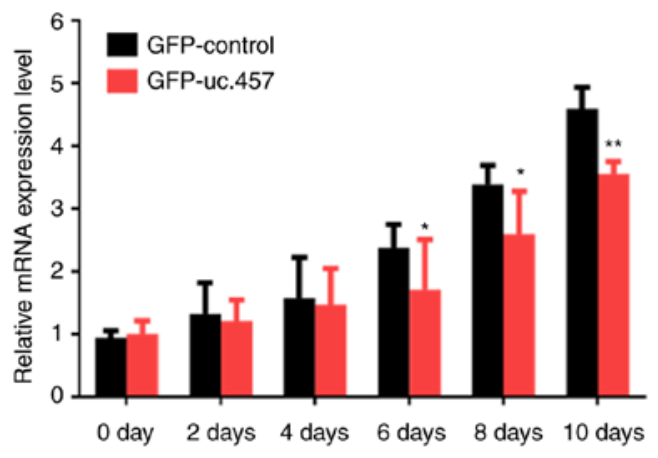

C

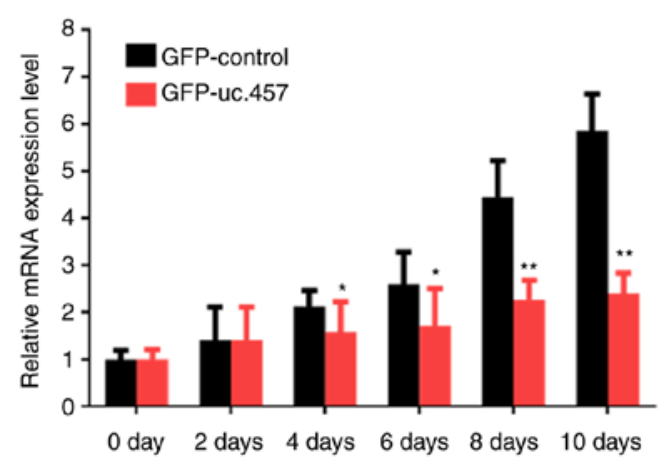

B

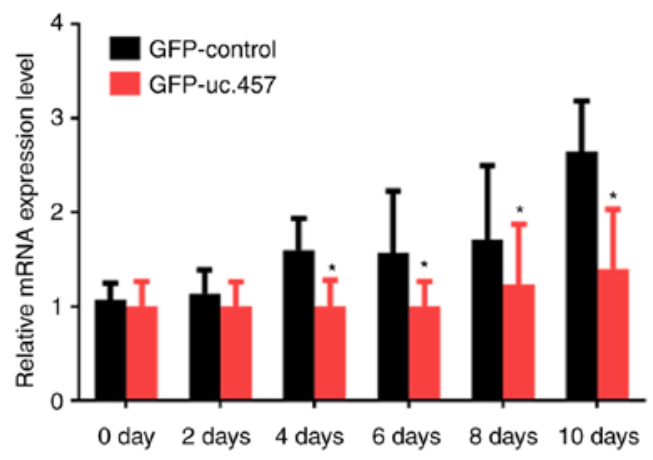

D

Mef2c

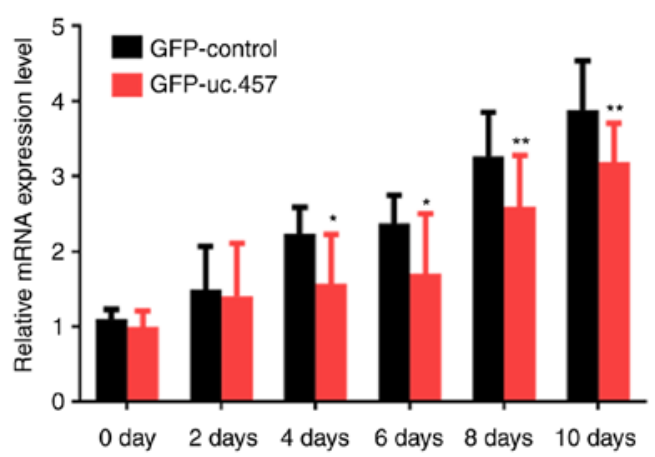

Figure 3. Uc.457 overexpression suppresses the dimethyl sulfoxide-induced differentiation of P19 cells. Expression levels of (A) HIRA, (B) NPPA, (C) cTnT, and (D) Mef2c following GFP-uc.457 or GFP-control plasmid transfection. N=3/group. Data are presented as the mean \pm standard deviation. ${ }^{*} \mathrm{P}<0.05$, ${ }^{* *} \mathrm{P}<0.01$ vs. GFP-control. cTnT, cardiac muscle troponin T; GFP, green fluorescent protein; HIRA, histone cell cycle regulation defective homolog A; Mef2c, myocyte-specific enhancer factor 2C; NPPA, natriuretic peptide A.

A

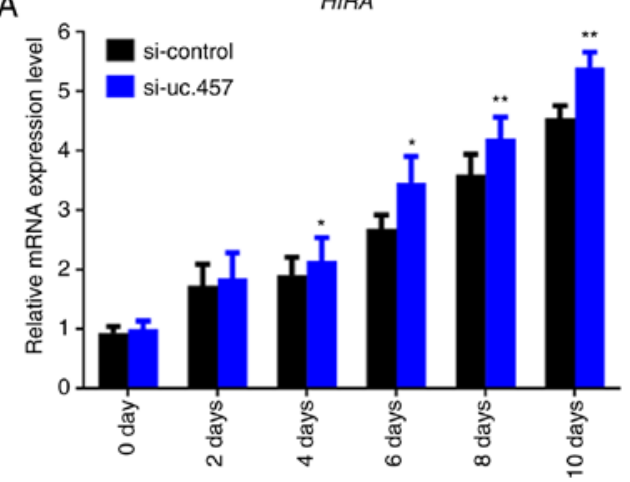

C

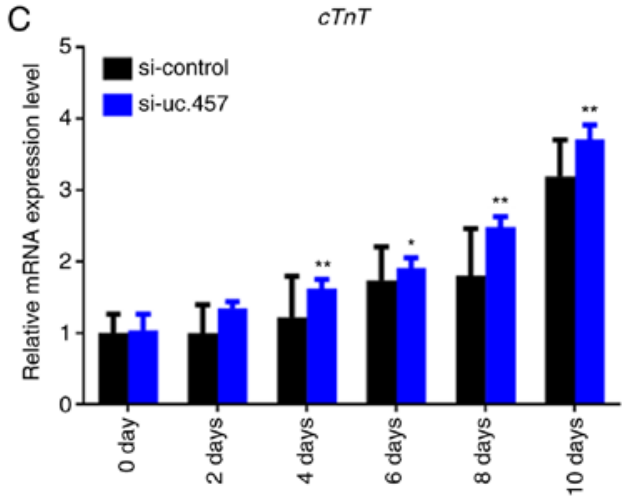

B

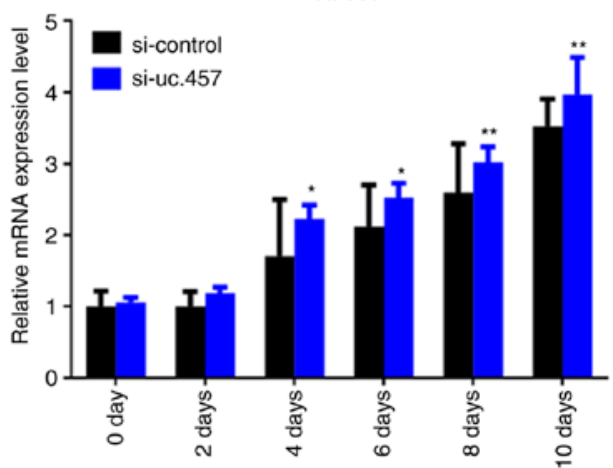

D

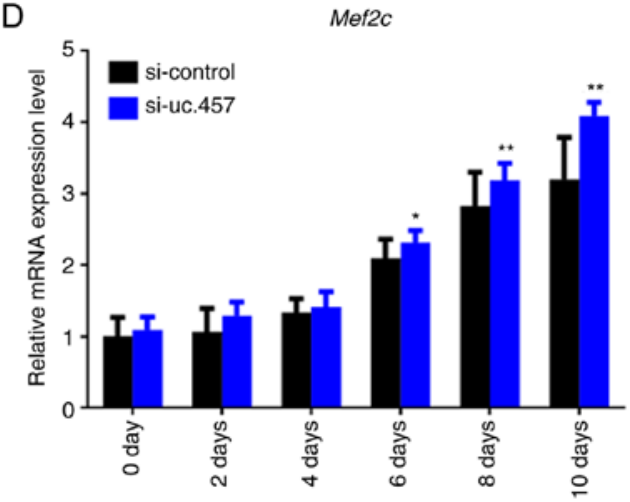

Figure 4. Uc.457 knockdown promotes the dimethyl sulfoxide-induced differentiation of P19 cells. Expression levels of (A) HIRA, (B) NPPA, (C) cTnT and (D) Mef2c following si-uc. 457 or si-control transfection. $\mathrm{N}=3$ /group. Data are presented as the mean \pm standard deviation. ${ }^{*} \mathrm{P}<0.05,{ }^{* *} \mathrm{P}<0.01 \mathrm{vs}$. si-control. cTnT, cardiac muscle troponin T; HIRA, histone cell cycle regulation defective homolog A; Mef2c, myocyte-specific enhancer factor 2C; NPPA, natriuretic peptide A; si, small interfering RNA. 
A

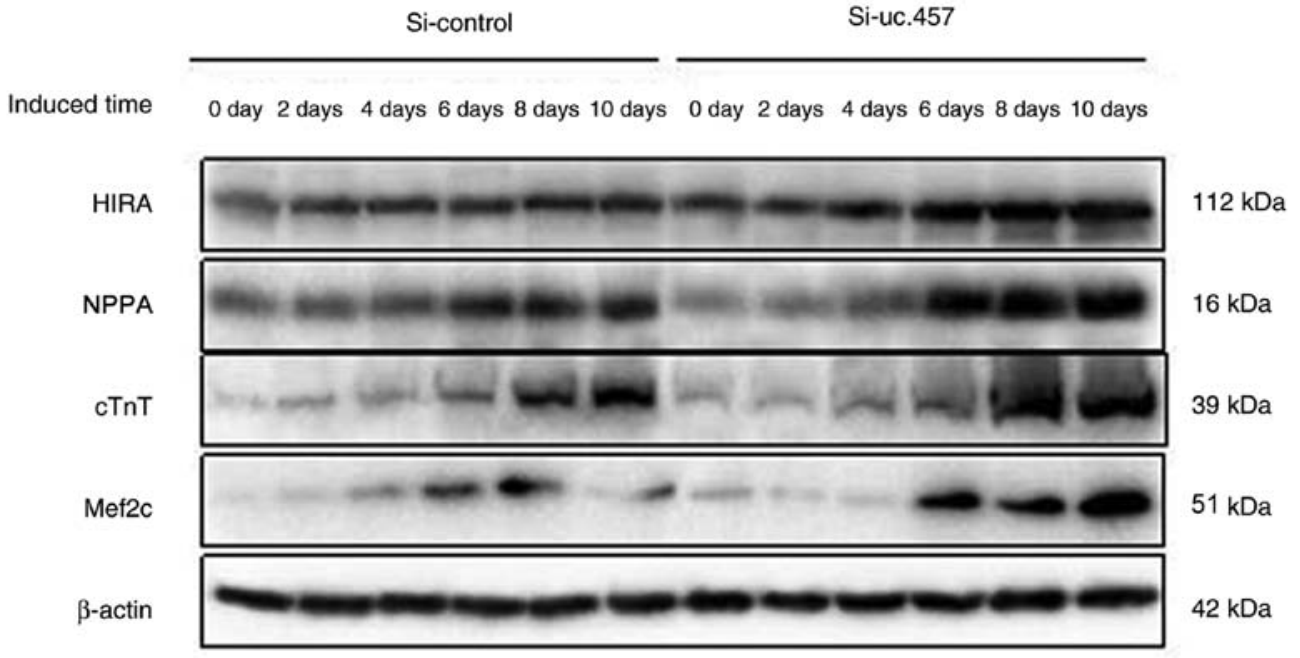

B

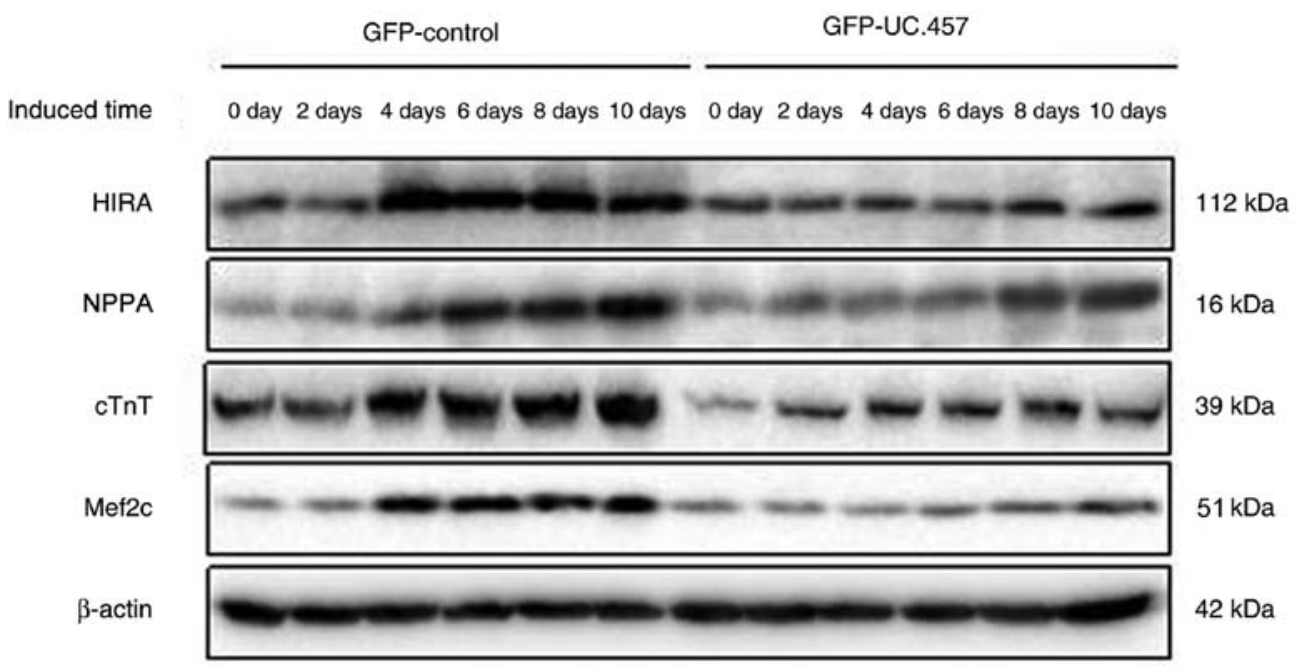

Figure 5. Uc.457 regulates the expression of genes associated with cardiomyocyte differentiation. (A) Expression levels of HIRA, NPPA, cTnT, and Mef2C following si-uc.457 or si-control transfection. (B) Expression levels of HIRA, NPPA, cTnT and Mef2c following GFP-uc.457 or GFP-control plasmid transfection. cTnT, cardiac muscle troponin T; GFP, green fluorescent protein; HIRA, histone cell cycle regulation defective homolog A; Mef2c, myocyte-specific enhancer factor 2C; NPPA, natriuretic peptide A; si, small interfering RNA.

that uc.457 is highly conserved among vertebrates and contains a binding site for the TFs, STAT (associated with the growth, survival and apoptosis of cardiomyocytes) and GATA1 (associated with cardiac development). In addition, the chromosomal region of uc.457 is enriched with H3K4me1, H3K9ac and H3K27ac histone modifications. Various studies have reported that histone lysine methylation is closely associated with heart development and CHD $(31,32)$. In the present study, P19 cells overexpressing uc.457 exhibited reduced proliferation compared with the control, whereas uc. 457 silencing increased proliferation, suggesting that uc.457 may affect cardiac development by regulating cell proliferation.

Additionally, during the differentiation of P19 cells into cardiomyocytes, it was revealed that overexpression of uc.457 downregulated the expression of HIRA, NPPA, cTnT and Mef2c. Song et al (33) reported that lncRNAs and cardiomyogenesis-associated RNAs act synergistically during cardiac differentiation; for example, co-expression of Mef2c and lncRNA uc.167 partially reversed the suppressive effects of lncRNA uc.167 on the proliferation, apoptosis, and differentiation of P19 cells. Long intergenic non-protein coding RNA, muscle differentiation 1 sequesters miR-135 to regulate the expression of Mef $2 c$, serving a role in the activation of muscle-specific gene expression (34). As an H3.3 chaperone, HIRA is a negative regulator of histone gene expression (35). It is highly conserved among various species and is differentially expressed during embryonic development; HIRA is important for embryonic survival and physiological development (35). It has been reported that mutations in HIRA prevent the axial rotation of embryos and normal heart looping, leading to CHD (36). HIRA is also located on the long arm of human chromosome 22, specifically at 22q11.2 (37). Therefore, it was considered that uc.457 may affect the differentiation of cardiac precursors into mature cardiomyocytes via an unknown mechanism.

P19 cells are characterized by a single genetic background with a simple method to induce differentiation compared with human embryonic stem cells, mesenchymal stem cells and induced pluripotent stem cells (15). Additional cell lines such as $\mathrm{H} 9 \mathrm{C} 2$ cells and in vivo experiments are required to further determine the roles of uc.457 in cardiac development. 


\section{Acknowledgements}

Not applicable.

\section{Funding}

The present study was supported by grants from the National Natural Science Foundation of China (grant nos. 81870167 and 81570209) and the Nanjing Medical Science and Technique Development Foundation (grant no. Ykk15148).

\section{Availability of data and materials}

All data generated or analyzed during the present study are included in this published article.

\section{Authors' contributions}

QZ performed the majority of the experiments and wrote the manuscript. ZC and ZY analyzed the data. CZ and LQ designed the study. All authors read and approved the final manuscript.

\section{Ethics approval and consent to participate}

Not applicable.

\section{Patient consent for publication}

Not applicable.

\section{Competing interests}

The authors declare that they have no competing interests.

\section{References}

1. Sadowski SL: Congenital cardiac disease in the newborn infant: Past, present, and future. Crit Care Nurs Clin North Am 21: 37-48, vi, 2009.

2. Srivastava D: Making or breaking the heart: From lineage determination to morphogenesis. Cell 126: 1037-1048, 2006.

3. van der Linde D, Konings EE, Slager MA, Witsenburg M, Helbing WA, Takkenberg JJ and Roos-Hesselink JW: Birth prevalence of congenital heart disease worldwide: A systematic review and meta-analysis. J Am Coll Cardiol 58: 2241-2247, 2011

4. Trojnarska O, Grajek S, Katarzyński S and Kramer L: Predictors of mortality in adult patients with congenital heart disease. Cardiol J 16: 341-347, 2009.

5. Blue GM, Kirk EP, Sholler GF, Harvey RP and Winlaw DS Congenital heart disease: Current knowledge about causes and inheritance. Med J Aust 197: 155-159, 2012.

6. Bruneau BG: The developmental genetics of congenital heart disease. Nature 451: 943-948, 2008.

7. Olson EN: Gene regulatory networks in the evolution and development of the heart. Science 313: 1922-1927, 2006.

8. de la Pompa JL and Epstein JA: Coordinating tissue interactions: Notch signaling in cardiac development and disease. Dev Cell 22: 244-254, 2012.

9. Batista PJ, Chang HY: Long noncoding RNAs: Cellular address codes in development and disease. Cell 152:1298-1307, 2013.

10. Frank S, Aguirre A, Hescheler J and Kurian L: A lncRNA perspective into $(\mathrm{Re})$ Building the heart. Front Cell Dev Biol 4-128: 2016.

11. Shen S, Jiang H, Bei Y, Xiao J and Li X: Long non-coding RNAs in cardiac remodeling. Cell Physiol Biochem 41: 1830-1837, 2017.

12. Ounzain S, Crippa S and Pedrazzini T: Small and long non-coding RNAs in cardiac homeostasis and regeneration. Biochim Biophys Acta 1833: 923-933, 2013.
13. Di Mauro V, Barandalla-Sobrados $M$ and Catalucci D: The noncoding-RNA landscape in cardiovascular health and disease. Noncoding RNA Res 3: 12-19, 2018.

14. Wang K, Liu F, Zhou LY, Long B, Yuan SM, Wang Y, Liu CY, Sun T, Zhang XJ and Li PF: The long noncoding RNA CHRF regulates cardiac hypertrophy by targeting miR-489. Circ Res 114: 1377-1388, 2014.

15. Klattenhoff CA, Scheuermann JC, Surface LE, Bradley RK, Fields PA, Steinhauser ML, Ding H, Butty VL, Torrey L, Haas $\mathrm{S}$, et al: Braveheart, a long noncoding RNA required for cardiovascular lineage commitment. Cell 152: 570-583, 2013.

16. Song G, Shen Y, Zhu J, Liu H, Liu M, Shen YQ, Zhu S, Kong X, Yu Z and Qian L: Integrated analysis of dysregulated lncRNA expression in fetal cardiac tissues with ventricular septal defect. PLoS One 8: e77492, 2013.

17. van der Heyden MA, van Kempen MJ, Tsuji Y, Rook MB, Jongsma HJ and Opthof T: P19 embryonal carcinoma cells: A suitable model system for cardiac electrophysiological differentiation at the molecular and functional level. Cardiovasc Res 58: 410-422, 2003

18. Wen J, Xia Q, Lu C, Yin L, Hu J, Gong Y, Yin B, Monzen K, Yuan J, Qiang B, et al: Proteomic analysis of cardiomyocytes differentiation in mouse embryonic carcinoma P19CL6 cells. J Cell Biochem 102: 149-160, 2007.

19. Livak KJ and Schmittgen TD: Analysis of relative gene expression data using real-time quantitative PCR and the 2(-Delta Delta C(T)) method. Methods 25: 402-408, 2001.

20. Hoelscher SC, Doppler SA, Dreßen M, Lahm H, Lange R and Krane M: MicroRNAs: Pleiotropic players in congenital heart disease and regeneration. J Thorac Dis 9 (Suppl 1): S64-S81, 2017.

21. Nemer M: Genetic insights into normal and abnormal heart development. Cardiovasc Pathol 17: 48-54, 2008.

22. Bajolle F, Zaffran S and Bonnet D: Genetics and embryological mechanisms of congenital heart diseases. Arch Cardiovasc Dis 102: 59-63, 2009.

23. Andersen TA, Troelsen Kde L and Larsen LA: Of mice and men: Molecular genetics of congenital heart disease. Cell Mol Life Sci 71: 1327-1352, 2014

24. Garg V, Kathiriya IS, Barnes R, Schluterman MK, King IN, Butler CA, Rothrock CR, Eapen RS, Hirayama-Yamada K, Joo K, et al: GATA4 mutations cause human congenital heart defects and reveal an interaction with TBX5. Nature 424: 443-447, 2003

25. Pabst S, Wollnik B, Rohmann E, Hintz Y, Glänzer K, Vetter H, Nickenig $G$ and Grohé C: A novel stop mutation truncating critical regions of the cardiac transcription factor NKX2-5 in a large family with autosomal-dominant inherited congenital heart disease. Clin Res Cardiol 97: 39-42, 2008.

26. Lander ES, Linton LM, Birren B, Nusbaum C, Zody MC Baldwin J, Devon K, Dewar K, Doyle M, FitzHugh W, et al: Initial sequencing and analysis of the human genome. Nature 409: 860-921, 2001.

27. Sallam T, Sandhu J and Tontonoz P: Long noncoding RNA discovery in cardiovascular disease: Decoding form to function. Circ Res 122: 155-166, 2018.

28. Zangrando J, Zhang L, Vausort M, Maskali F, Marie PY, Wagner DR and Devaux Y: Identification of candidate long non-coding RNAs in response to myocardial infarction. BMC Genomics 15: 460, 2014.

29. Kurian L, Aguirre A, Sancho-Martinez I, Benner C, Hishida T, Nguyen TB, Reddy P, Nivet E, Krause MN, Nelles DA, et al: Identification of novel long noncoding RNAs underlying vertebrate cardiovascular development. Circulation 131: 1278-1290, 2015.

30. Grote P, Wittler L, Hendrix D, Koch F, Währisch S, Beisaw A, Macura K, Bläss G, Kellis M, Werber M and Herrmann BG: The tissue-specific lncRNA Fendrr is an essential regulator of heart and body wall development in the mouse. Dev Cell 24: 206-14, 2013.

31. Ang SY, Uebersohn A, Spencer CI, Huang Y, Lee JE, Ge K and Bruneau BG: KMT2D regulates specific programs in heart development via histone H3 lysine 4 di-methylation. Development 143: 810-821, 2016.

32. Cloos PA, Christensen J, Agger K and Helin K: Erasing the methyl mark: Histone demethylases at the center of cellular differentiation and disease. Genes Dev 22: 1115-1140, 2008.

33. Song G, Shen Y, Ruan Z, Li X, Chen Y, Yuan W, Ding X, Zhu L and Qian L: LncRNA-uc.167 influences cell proliferation, apoptosis and differentiation of P19 cells by regulating Mef2c. Gene 590: 97-108, 2016 
34. Cesana M, Cacchiarelli D, Legnini I, Santini T, Sthandier O, Chinappi M, Tramontano A and Bozzoni I: A long noncoding RNA controls muscle differentiation by functioning as a competing endogenous RNA. Cell 147: 358-369, 2011.

35. Szenker E, Lacoste N and Almouzni G: A developmental requirement for HIRA-dependent $\mathrm{H} 3.3$ deposition revealed at gastrulation in Xenopus. Cell Rep 1:730-740, 2012.
36. Dilg D, Saleh RN, Phelps SE, Rose Y, Dupays L, Murphy C, Mohun T, Anderson RH, Scambler PJ and Chapgier AL: HIRA is required for heart development and directly regulates Tnni2 and Tnnt3. PLoS One 11: e0161096, 2016.

37. Ju ZR, Wang HJ, Ma XJ, Ma D and Huang GY: HIRA gene is lower expressed in the myocardium of patients with tetralogy of fallot. Chin Med J (Engl) 129: 2403-2408, 2016. 